\title{
Gastrointestinal Stromal Tumors: Diagnostic and Therapeutic Challenges
}

Ibrahim Abdelkader Salama ${ }^{1 *}$, Waleed Hammam Mosa ${ }^{2}$, Mohamed Elsherbini ${ }^{3}$, Mohamed Abbasy ${ }^{4}$ Mohamed Houseni $^{5}$ and Mohamed Badr $^{6}$

${ }^{1}$ Department of Surgery, National Liver Institute, Menophyia University, Egypt

${ }^{2}$ Department of Oncology, Faculty of medicine, Cairo University, Egypt

${ }^{3}$ Department of Clinical Oncology, Faculty of medicine, Menophyia University, Egypt

${ }^{4}$ Department of Hepatology, National Liver Institute, Menophyia University, Egypt

${ }^{5}$ Department of Radiology, National Liver Institute, Menophyia University, Egypt

${ }^{6}$ Department of Pathology, National Liver Institute, Menophyia University, Egypt

\section{Abstract}

Background: Gastrointestinal stromal tumors (GIST) are the most common mesenchymal neoplasms of the digestive system. They originate from the interstitial cells of Cajal and are characterized by the over expression of KIT protein (Tyrosine Kinase), and they pose a diagnostic and therapeutic dilemma.

Objective: A challenge in diagnosis and treatment of GIST

Patients \& Methods: This is a retrospective study of GIST cases that diagnosed and treated in our center during the past 5 years. These studies include clinical characteristics, imaging techniques, neoadjuvant therapy, surgical techniques, immunohistochemistry, and prognosis of such cases.

Results: Sixteen patients were diagnosed as having GIST (12 males/4 females) with a mean age 62 years (31-83 years). Diagnosis was made preoperatively in 11 patients $(69 \%)$ and intraoperatively with histopatholgical confirmation in five patients $(31 \%)$. The site of the tumor was detected in the stomach in 6 cases $(37.5 \%)$, one in duodenum $(6.25 \%)$, five in small intestine $(31.25 \%)$, one in mesentery $(6.25 \%)$, two in colon $(12.5 \%)$ and one rectal GIST $(6.25 \%)$. The main presentation of the disease was anemia, GIT bleeding and abdominal mass. Fourteen patients considered resectable and they were operated upon $(87.5 \%)$ and in two patients $(12.5 \%)$ neadjuvant therapy was started with favorable response in one case and poor response in other one with advanced GIST. All patients received Imatinib as adjuvant therapy. Mean follow up period was 33 months (4-54 months).

Conclusion: GIST is a complex and challenging disease that requires a multidisciplinary approach in specililized center for better prognosis of such disease.

Keyword: Gastrointestinal stromal tumors; Neoadjuvant therapy; c-KIT treatment; Prognosis

\section{Introduction}

Gastrointestinal Stromal Tumor (GIST) is the most common mesenchymal tumor of the gastrointestinal (GI) tract, $[1,2]$ account for $<1 \%$ of all digestive tract tumors $[3,4]$.

GIST can develop anywhere along the whole GI tract from the esophagus to the rectum, however, stomach $(60 \%)$ and small intestine (30\%) are the most common locations for GIST. Only $10 \%$ of GISTs are found in the esophagus, mesentry, omentum, colon or rectum. Upto $30 \%$ of GIST exhibits high -risk (Malignant) behavior such as metastasis and infiltration [5-8].

The metastatic pattern is predominantly intra-abdominal spread throughout the peritoneal cavity and to the liver, but lymphatic spread is uncommon [9].

GIST presents overexperssion of the transmemebrane protein KIT (Tyrosine Kinase) Receptor, coded by c-Kit proto-oncogene located in chromosome $4\left(49^{11}-9^{12}\right)$ believed to control cell proliferation and apoptosis $[10,11]$. This protein expression allows the differentiation and diagnosis of these tumors using CD117 monoclonal antibody, which is positive in $>95 \%$ of stromal tumors, however, in $5 \%$, of neoplasms the result are negative for CD 117 (KIT- negative GIST) [11,12].

GIST demonstrates almost equal distribution between males and females, however some literatures suggest that there is a slight male predominance [13].

Although GIST has been reported in patients of all ages, including children, most of them are between the age of 40-80 years at the time of presentation, with a median age of 60 years. The majority of GISTs are sporadic nonetheless; there are several cases reports of familial germline mutations in KIT proto-oncogenes [13].

The clinical manifestations of GISTs are variable and rendering accurate diagnosis challenging. The current diagnoses of GISTs are based on histological and immunohistochemical criteria, the most important of which is the expression of the receptor tyrosine kinase KIT (CD117, c kit) [14,15].

Imaging in the form of contrast-enhanced computed tomography (CECT) is the modality of choice. It is used to characterize the lesion, evaluate its extent, and assess the presence or absence of metastasis at the initial staging workup. CECT also used for monitoring response to therapy and performing follow -up surveillance of recurrence. [12,16].

${ }^{*}$ Corresponding author: Ibrahim Abdelkader Salama M.D., Department of Hepatobiliary Surgery, National Liver Institute, Menophyia University, Shiben Elkom, Egypt, Tel: (20) 2 3304323; Fax: (20) 48 2234586; E-mail: ibrahim_salama@hotmail.com

Received June 25, 2014 ; Accepted August 25, 2014; Published September 20 2014

Citation: Salama IA, Mosa WH, Elsherbini M, Abbasy M, Houseni $M$, et al. Gastrointestinal Stromal Tumors: Diagnostic and Therapeutic Challenges. Journal of Surgery [Jurnalul de chirurgie] 2014; 10(2): 159-165 DOI: 10.7438/1584-9341-10-2-11

Copyright: @ 2014 Salama IA, et al. This is an open-access article distributed under the terms of the Creative Commons Attribution License, which permits unrestricted use, distribution, and reproduction in any medium, provided the original author and source are credited. 
Endoscopic ultrasound (EUS) has been used in the diagnosis of GIST; it assesses the depth of invasion and is useful in obtaining a tissue sample. Preoperative percutaneous biopsy should not be used because of a significant tumor rupture or dissemination [12].

GISTs are positron emission tomography (PET) avid tumors because the receptor tyrosine kinase increases the glucose transport protein signaling [12]. PET is useful in revealing small metastasis which would otherwise not picked up on CECT as it helps differentiate an active tumor from necrotic or inactive scar tissues [6].

PET also differentiates malignant from benign tissues and recurrent tumor from nondescript benign changes. Changes in the metabolic activity of tumors precede anatomic changes on CECT: it is hence used to assess complex metastatic disease in patients who are being considered for surgery $[17,18]$.

Surgery is the primary treatment of choice for all tumors which can be resected without significant morbidity. Conventional chemotherapy and radiotherapy are not usually effective. Imatinib mesylate is a potent and specific inhibitors of the KIT-Protein tyrosine -kinase and has been approved for the treatment of KIT (CD117) positive irresectable or metastatic cases of GISTs as it plays an integral role in the treatment of GISTas a neoadjuvant and adjuvant therapy [19].

Imatinib is effective in reducing the like hood of negative margins without significant morbidity $[20,21]$.

The purpose of this study is to present the challenges in the diagnosis and treatment of GIST cases in our institute during the past 5 years and compare the results obtained with the results of other centers.

\section{Patients and Methods}

This review retrospective study in sixteen patients with GIST, that operated upon at the department of surgery, National liver Institute, Menophyia University in association with Clinical oncology department in Cairo University and Menophyia University from January 2009 to January 2014.

This clinical study was based upon reviewing the patients data retrieved from the medical records with ethical and scientific approval.

Disease presentation and diagnostic methods were analyzed including upper GIT endoscopy, lower GIT endoscopy, ultrasound, endoscopic ultrasound (EUS), contrast-enhanced computed tomography (CECT), fine needle aspiration (FNAB), large core needle biopsy (LCNB) and positron emission tomography (18F-FDG-PET).

Tumors were assessed for resectability as well as complete removal of the neoplasm. Imatinib was used as a neoadjuvant therapy for the cases that diagnosed as having locally advanced or metastatic tumors, with continuation as adjuvant therapy for all cases after surgery.

Surgical techniques depend on the site of the tumor and the possibility of complete resection intra-operatively.

Histological parameters were reviewed by experienced pathologists for histological confirmation of the diagnosis of GIST and evaluation of the morphological and immunohistochemical characteristics. Tumor size and necrosis on fresh specimen was examined. The mitotic rate was assessed by counting the number of mitoses per 50 high-power field (HPF) and imunnohistochemical markers (CD 117), (CD 34), Vimentin, smooth muscle actin and S-100 protein in all patients. Microscopic positive margins $(<1 \mathrm{~mm})$ and, in some cases, cell proliferation index measures through $\mathrm{Ki}-67$. The tumors were classified according to risk prognosis using Fletcher's classification in accordance with the U.S. National Institute of Health (NIH) guidelines as very low risk, low risk, intermediate risk and high risk [12].

According to the risk prognosis guidelines and intraoperative tumor breakage, Imatinib was given postoperatively.
Follow up was carried out at 1,3,6 months after surgery then yearly using CT scan and in some cases PET scan was used in order to assess the possibility of local recurrence or distal metastasis, and disease free period.

\section{Results}

Sixteen patients were diagnosed with GIST tumors, twelve patients' males $(75 \%)$ and four females (25\%) with average age 62 years (31-83 years of age). Among those patients 11 cases (69\%) were diagnosed as GIST preoperatively by radiological, histopathological \& immunohistochemesity examination.

Five cases were diagnosed as suspicious GIST intraoperatively and confirmed postoperatively by histopathological examination of surgical specimens; these cases were classified as, one gastric GIST, one Duodenal GIST, one mesenteric GIST and two intestinal GISTs.

Tumors location of this series were as follows: six in stomach, one in duodenum, five in small intestines, one in the mesentery, two in colon and one in the rectum.

All patients presented with different signs and symptoms such as anemia in 14 cases (87.5\%), gastrointestinal bleeding in 5 cases $(31.25 \%)$, abdominal pain in 4 cases $(25 \%)$, palpable mass in 5 cases (31.25\%), nausea, vomiting and early satiety in 3 cases $(18.75 \%)$, constipation in 2 cases (12.5\%) and weight loss in 6 cases (37.5\%), most of the patients has one or more symptoms at the time of presentation.

CT scan with oral \& intravenous contrast was used as a gold standard diagnostic test for all patients (Figure 1). UGI endoscopy plus biopsy was used in 4 patients (25\%) with positive for GIST in only 2 cases (Figure 2). Endoscopic ultrasound (EUS) was used in 3 patients (18.75\%) (Figure 3). Large core needle biopsy (LCNB) was done in 2 cases $(12.5 \%)$ in large tumor to confirm the diagnosis and to start neoadjuvant therapy.

Fludoexyglucose positron emission tomography (18F-FDG-PET)
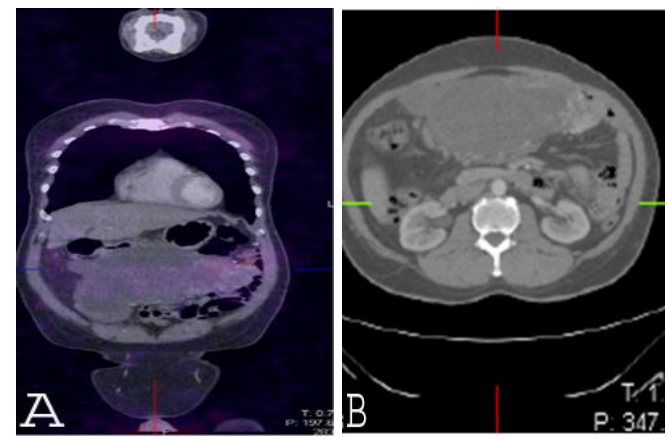

Figure 1: Abdominopelvic CT scan for Gastric GIST Tumor $33 \mathrm{~cm}$ in Diameter A. Coronal Section B. Axial Section (Huge intrabdominal swelling occupied the abdomen and pelvis).
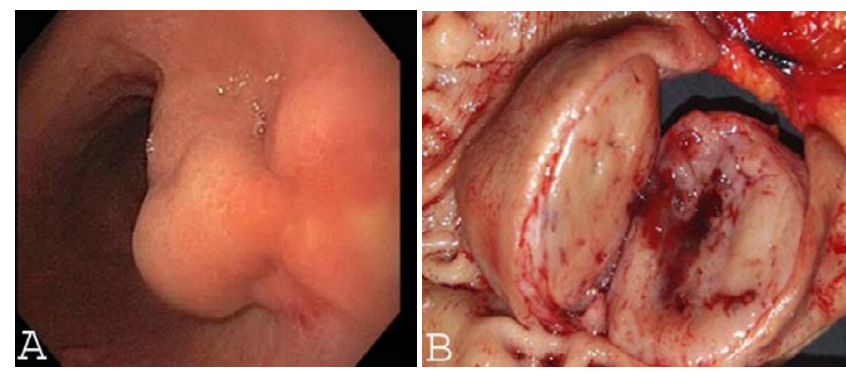

Figure 2: Gastric GIST Tumor A. Upper Endoscopy B. Tumor bisected after Excision. 
was carried out before starting and after-neoadjuvant Imatinib therapy for follow up response in 5 cases (31.25\%).

Fourteen patients were diagnosed as resectable tumors and were operated upon (87.5\%). Nine patients were diagnosed preoperatively and 5 patients were assessed for resectability intraoperatively. In two patients that were considered unresectable at the initial assessment (12.5\%) one had advanced tumor and the other had metastatic spread at the time of presentation therefore they received $400 \mathrm{mg} /$ day Imatinib as neoadjuvant therapy for 6 months, with good response in one patient with huge gastric GIST (about $33 \mathrm{~cm}$ in diameter) revealed by PET scan and the patient become a surgical candidate (Figure 4). On the other hand the second patient had metastasis with poor response to neoadjuvant therapy and still on the treatment since 2 years.

Surgery was the treatment of choice for 15 patients (93.75\%) aiming to remove the disease in all cases. The type of surgery depends upon the location of the tumor: 4 patients did partial gastrectomies, 2 patients did distal gasterctomies (Figure 4) one duodenopancreatectomy (Whipple's operation) (Figure 5), one mesenteric excision with adjacent intestinal resection, (Figure 6) 5 intestinal resection, (Figure 7) one transverse colectomy, and one anterior resection for rectal GIST ,with all negative safety margins (Table I).

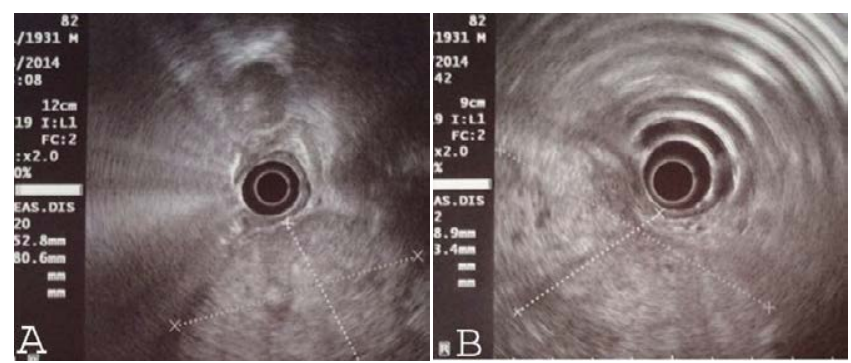

Figure 3: Endoscopic Ultrasound of Gastric GISTA.GIST $5 \times 8 \mathrm{~cm}$ in diameter $\mathrm{B}-8 \times 4 \mathrm{~cm}$ in diameter.
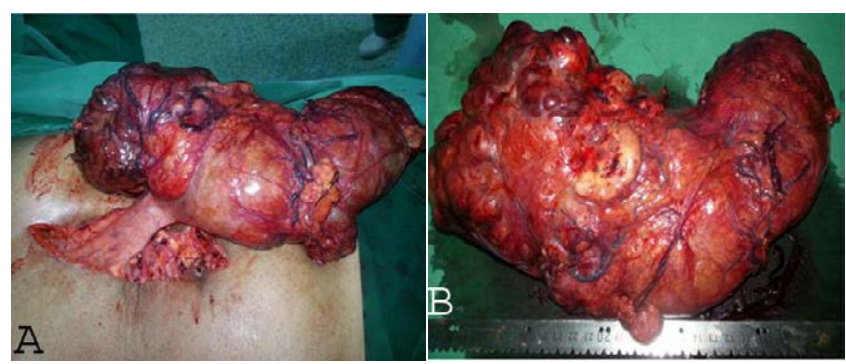

Figure 4: Huge gastric GIST $33 \mathrm{~cm}$ in diameter with wedge resection of the stomach.

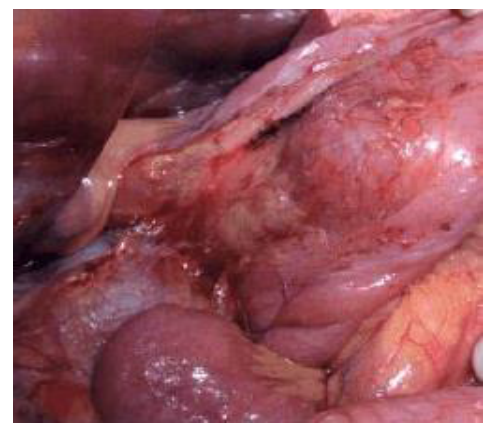

Figure 5: Duodenal GIST treated with pancreaticoduodenectomy (Whipple's operation).

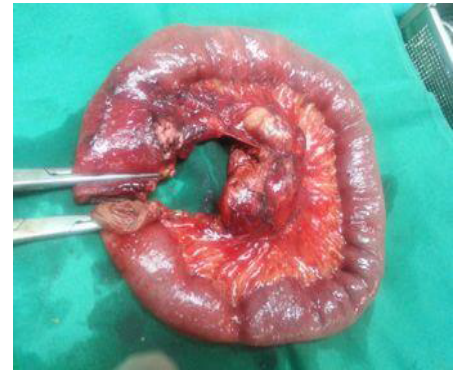

Figure 6: Mesenteric GIST with segmental resection of adjacent bowel.

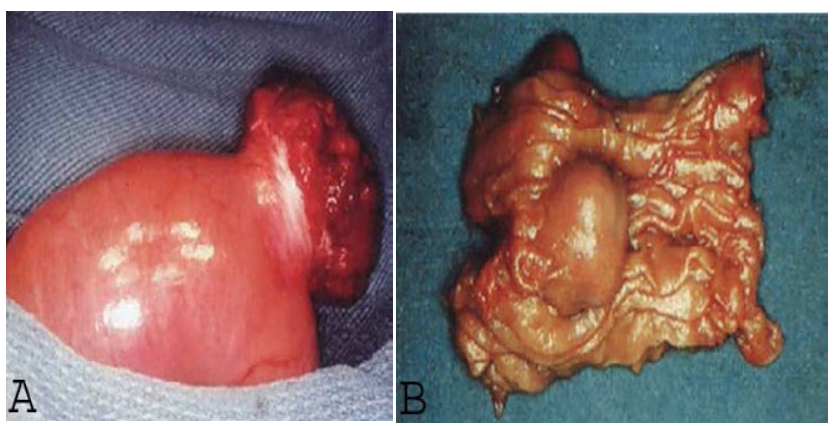

Figure 7: Intestinal GIST A. Intestinal GIST B. Resected intestinal GIST.

Table I: Operative procedures performed in 15 GIST Tumors out of 16 Tumors.

\begin{tabular}{|c|c|c|}
\hline \multirow{2}{*}{ Origin of GIST } & \multirow{2}{*}{ Type of Resection } & No. $\%$ \\
\hline & & 15 cases \\
\hline \multirow[t]{2}{*}{ Stomach (6) } & \multirow{2}{*}{$\begin{array}{l}\text {-Partial or wedge gastric resection } \\
\text {-Distal gastric resection }\end{array}$} & (4) $26.66 \%$ \\
\hline & & (2) $13.33 \%$ \\
\hline Duodenum (1) & $\begin{array}{l}\text {-Pancreaticodudenectomy (Whipple's } \\
\text { operation) }\end{array}$ & (1)6.66\% \\
\hline Intestine (5) & -Small bowel segmental resections & (5) $33.33 \%$ \\
\hline Mesentery (1) & $\begin{array}{l}\text {-Mesenteric excision with adjacent intesti- } \\
\text { nal segmental resection }\end{array}$ & (1) $6.66 \%$ \\
\hline Colon (1) & $\begin{array}{l}\text {-Transverse colectomy + Segmentectomy } \\
\text { seg.7 (Metastatectomy) }\end{array}$ & (1) $6.66 \%$ \\
\hline Rectum (1) & -Anterior resection & (1) $6.66 \%$ \\
\hline
\end{tabular}

Histological analysis revealed: 8 tumors (50\%) had a mitotic index $<5$ mitosis/50 HPF, 5 tumors (31.25\%) had a mitotic index $>10$ mitosis/ HPF and 3 tumors (18.75\%) had necrosis. Classification of tumors according to Fletcher prognostic scale was as follow 5 tumors $(31.25 \%)$ with low risk, three tumors $(18.75 \%)$ with moderate risk and eight tumors (50\%) with high risk (Table II).

According to the cell type 10 tumors (62.5\%) were fusiform (spindle) cell, 4 tumors (25\%) were epitheliod cell and 2 tumors $(12.5 \%)$ were mixed types (Figure 8).

Average tumor size was ranged from $3.5 \mathrm{~cm}$ to $33 \mathrm{~cm}$ in diameter. The average tumor weight from $200 \mathrm{mg}$ to $11 \mathrm{~kg}$.

Immunohistchemistry study revealed 14 neoplasms (87.5\%) positive for CD 117 and CD 34, five patients positive for vimentin and actin (31.25\%) and four patients positive for S-100 protein (12.5\%) (Figure 9).

Average hospital stays 6.5 days (4-20 days)

There was no mortality in this series but there was 3 morbidity (one patient with wound infection, one patient with lung collapse both treated conservatively and one patient with incisional hernia treated surgically with mesh)

Five patients (31.25\%) received $400 \mathrm{mg} /$ day Imatinib as 
Table II: Fletcher Prognostic Classification of 16 GIST Tumors.

\begin{tabular}{|c|c|c|c|}
\hline Risk & Size (cm) & Proliferation index (Mitotic count) & $(\mathrm{No}=16) \%$ \\
\hline Very low & $<2 \mathrm{~cm}$ & $<5 / 50 \mathrm{HPF}$ & $(n=0) 0 \%$ \\
\hline LOW & $2-5 \mathrm{~cm}$ & $<5 / 50 \mathrm{HPF}$ & $(n=5) 31.25 \%$ \\
\hline Medium & $\begin{array}{l}<5 \mathrm{~m} \\
5-10 \mathrm{~cm}\end{array}$ & $\begin{array}{l}\text { 6- } 10 / 50 \mathrm{HPF} \\
<5 / 50 \mathrm{HPF}\end{array}$ & $(n=3) 18.75 \%$ \\
\hline High & $\begin{array}{l}>10 \mathrm{~cm} \\
\text { Any }\end{array}$ & $\begin{array}{l}\text { Any } \\
>0 / 50 \mathrm{HPF}\end{array}$ & $(n=8) 50 \%$ \\
\hline
\end{tabular}

HPF, high power field

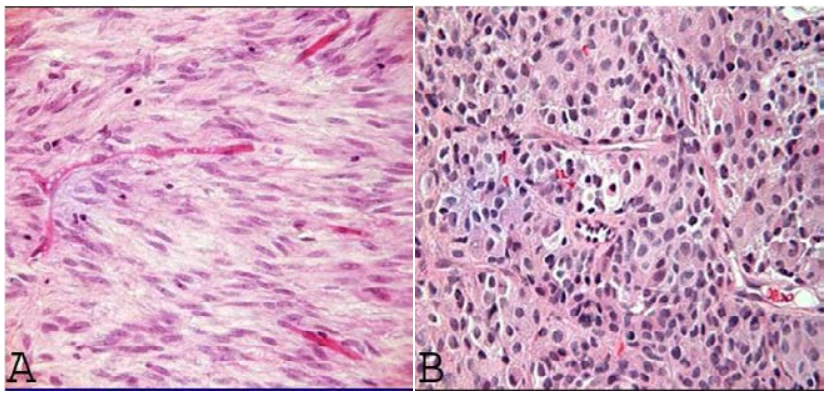

Figure 8: Histopathology of GIST Tumor A. Spindle cell B. Epitheliod cell.

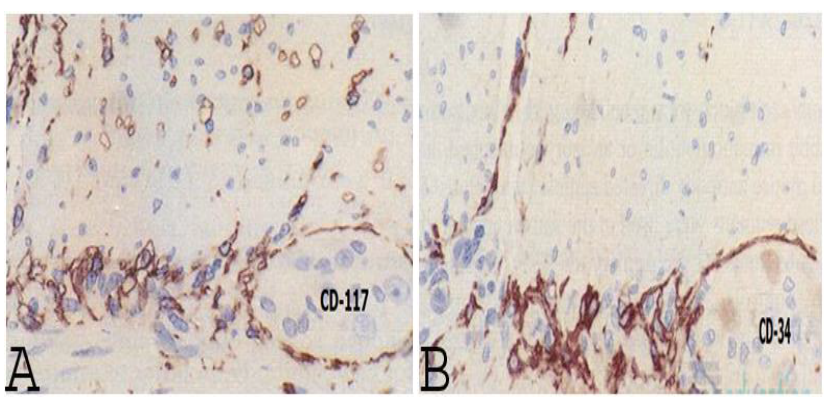

Figure 9: immunohistochemeistry of GIST Tumors A. CD117 Positive B. CD 34 Positive.

neoadjuvant therapy for 3-6 months to decrease the size of the tumor preoperatively and then surgical intervention depends on the response to therapy. All patients received Imatinib postoperative as adjuvant therapy for 6 months. One patient considered not a candidate for surgery due to advanced and metastatic disease, received Imatinib for 24 months and still on treatment.

Average follow up was 33 months (4-54 months) during follow up period two patients developed metastasis in the liver. One patient did transverse colectomy for colon GIST presented with metastasis in the segment VII of the right lobe of the liver for which segmentectomy of segment VII (Metastatectomy) was done (Figure 10), the other patient had huge liver metastasis central in the liver about $20 \times 25 \mathrm{~cm}$ in diameter 6 months after intestinal GIST resection and the patient put on Imatinib therapy for 1 year with poor response, but the course still stationary (Figure 11).

\section{Discussion}

Gastrointestinal stromal tumors (GISTs) are common mesenchymal tumors that arise predominantly in the gastrointestinal tract (GIT). In the past, there has been considerable debate regarding its nomenclature, cellular origin, diagnosis and prognosis [22-24]

Due to their similar appearance by light microscopy, GISTs were previously thought to be smooth muscle neoplasms and most were classified as liomyomas, liomyoblastomas, liomyosarcomas or schwannomas [24]. It was in 1998, after the discovery of gain-of function mutations in the c-KIT proto-oncogene that these tumors were reliably distinguished from other histopathological subtype of mesenchymal tumors [22,25].

GISTs represent the most common mesenchymal neoplasms of the GIT with an incidence o.1-3.0 \% for malignancy transformation $[26,27]$. It is thought that these tumors differentiate from intestinal pace maker cells, also known as interstitial cell of Cajal [28].

They affect mostly males between the ages of 50 and 70 years, but it can be discovered incidentally at young age groups. Large or advanced lesions may present with a variety of clinical findings, include bleeding, abdominal pain, early satiety, bowel obstruction or perforation $[29,30]$.

The most frequent location of GIST is the stomach $(60-70 \%)$ followed by the small intestine (20-30\%), colorectal $(<5 \%)$, esophagus $(<2 \%)$, with lower frequency in the peritoneum, mesentery and omentum [31]. Our series showed a higher prevalence in the stomach (37.5\%) followed by small intestine (31.25\%) and colon (12.5\%), which constitute with what has been reported in the literatures.

Only $70 \%$ of patients with GIST are symptomatic while $20 \%$ are asymptomatic in which the tumors are detected incidentally, $10 \%$ of the lesions are detected only at autopsy, symptoms and signs are not disease specific, and are related more to the site of the tumor [27,32]. Anemia considered a predominant sign for all cases of GIST $[33,34]$ and this constitutes with our series as anemia represent $87.5 \%$ of the cases. Bleeding comprises the most common symptoms after anemia (30-40\%), and it is attributed to the erosion into GIT lumen causing hematemesis, melena, or anemia which is usually more chronic on presentation [27-32].

The symptoms reported in our series were similar to those reported in the literatures.

Diagnosis was occasionally incidental while studying another disease through imaging studies, suspected cases intraperativelly or through histological study from surgical specimen obtained as

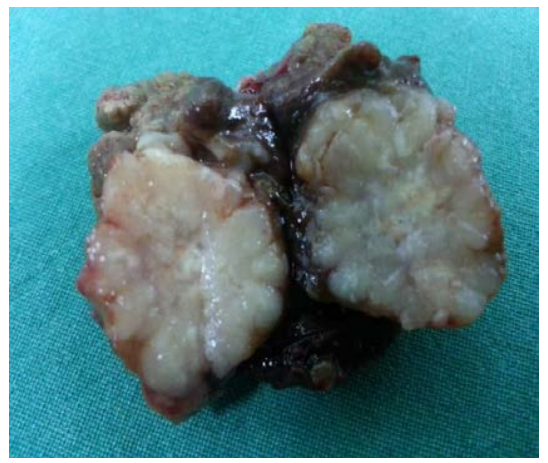

Figure 10: Metastatectomy of segment VII of the liver after transverse colectomy for Colonic GIST.
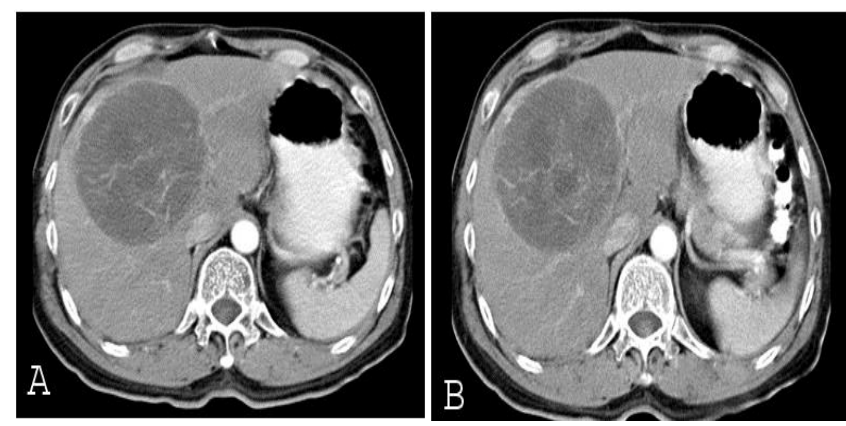

Figure 11: Hepatic Metastasis from Intestinal GIST A. Pre-Imatinib therapy $B$.Post-Imatinib therapy (Shows limited response to the therapy). 
occurred in $(31.25 \%)$ in our cases, but the diagnosis was confirmed preoperatively in $(68.75 \%)$ of cases.

CT scan using oral and intravenous contrast is the method of choice for patients with suspected abdominal tumor. CT scan reveals exophytic heterogenous, vascular tumors associated with hemorrhage and necrosis [35].

In our series CT was the method of choice for diagnosis and follow up.

Upper GIT endoscopy for gastro-duodenal or esophageal cases usually shows a protruding submucosal lesion with or without mucosal ulcer [36].

Endoscopic biopsy usually does not provide sufficient evidence to establish GIST diagnosis because of its submucosal nature [37].

This also occurred in our study as endoscopy was carried out in 4 cases of gastro duodenal GIST with submucosal lesion and endoscopic biopsy confirm the diagnosis of GIST only in two out of 4 cases.

Endoscopic Ultrasound (EUS) can detect small GIST tumors (round or oval, hypoechogenic and those found in muscularis propria), allowing the study of the relationship between different sheets of the gastrointestinal wall. Echo endoscopic puncture has a better outcome than endoscopic biopsy with a success rate of $80 \%-90 \%$ [38]. Only 3 patients of our series with suspected GIST in the gastric wall were subjected to EUS and the diagnosis of GIST tumor was confirmed by FNAB guided through EUS.

The Task Force Report (NCCN GIST) does not recommend carrying out preoperative biopsy from easily resectable tumors because this may lead to hemorrhage and dissemination [34,35]. However, locally advanced tumors that might be treated using Imatinib required immunohistochemical study on CD 117. Two cases of our series (12.5\%) that had locally advanced tumors required large core needle biopsy (LCNB) to achieve the diagnosis of GIST. Imatinib started as a neoadjuvant therapy to down stage the tumors. One patient had a good response after treatment with Imatinib for 6 months, and the GIST become surgically resectable, the other one had poor response to the treatment.

PET-18F-FDG offers information about metabolic activity and allows the estimation of neoplastic malignancy because a higher glucose uptake represents higher metabolic activity and, therefore, this suggests a more aggressive tumor [36]. Also, this technique has high sensitivity in assessing early-and long-term response to Imatinib in patients with advanced GIST positive to CD $117[39,40]$. However, CT scan is more cost-effective in suspected abdominal tumor.

Tumor response is assessed for other entities as size decrease according to RECIST criteria (Response Evaluation Criteria in Solid Tumor. However, these criteria may underestimate response for GIST neoplasms because there are several changes revealed by CT scan in addition to tumor size changes, especially the addition of intratumoral nodules or decreased vascalarization [41].

Choi et al concluded that CT scan is sensitive and specific to assess metastatic GIST response to Imatinib, considering response as size decrease $>10 \%$ or tumor density decrease $>15 \%$ at 2 months after the initiation of therapy with a $97 \%$ sensitivity, and $100 \%$ specificity, when compared to PET response [17].

The consensus conference of Lugano [35] established that PET should be used when an early assessment of tumor response to Imatinib is required to consider surgery or when there is some confusion that raises suspicion of metastasis. In our series, only five patients were diagnosed and follow up using PET pre-neoadjuvant Imatinib therapy and follow up response of this therapy. The rest of patients were studied using CT scan with $100 \%$ sensitivity. MRI provides more valuable information than CT scan for rectal GIST [36]. In our series, one case of rectum the MRI used in evaluation and follow up.

GIST vary greatly in size from a few millimeters to more than $30 \mathrm{~cm}$, the median size being between $5 \mathrm{~cm}-8 \mathrm{~cm}$. Macroscopically, GIST usually has an exophytic growth and a common intra-operative appearance is that a mass attached to the stomach, projecting into the abdominal cavity and displacing other organs [26,32]. On gross appearance they are smooth gray, and white tumors which are well circumscribed, usually with a pseudo capsule. A small area of hemorrhage or cystic degeneration and necrosis may be visible [32]. In our series one tumor size reaches $33 \mathrm{~cm}$ in diameter and weight up to $11 \mathrm{~kg}$ which constitute with other reports in literatures.

Because there is a wide range of differential diagnosis of GIST histology, these tumors are confirmed through immunohistochemical and molecular biological techniques with c-KIT overexpression (CD117) as the key marker. Approximately $>75 \%$ of tumors are c-KIT positive for $\mathrm{CD} 117$, whereas $60-70 \%$ are positive to $\mathrm{CD} 34,30-40 \%$ positive to Vimentin \& smooth muscle Actin, $5 \%$ to S-100 protein and $1-2 \%$ to desmin or Keratin $[5,7,9,32]$. In our series $87.5 \%$ of cases positive for CD117 \& CD34, 31.25\% for Vementin \& Actin while 25\% positive for S-protein, which is similar to the results reported in other literatures.

GIST has three essential histological patterns, $70 \%$ fusiform (spindle) apparently with the best survival rate, 20\% epitheliod and $10 \%$ mixed. C-KIT negative GIST are usually epitheliod and extraintestinal [42]. In our cases, fusiform (spindle) histological pattern are the predominant type (62.5\%), followed by the epitheliod type (25\%) and mixed type (12.5\%).

Based on studies by Fletcher et al. [12] the two most important prognostic variables for GIST are tumor size $(<2 \mathrm{~cm}, 2-5 \mathrm{~cm},>5 \mathrm{~cm})$ and mitosis index per 50 high-power fields (HPF) $(<5$ mitosis/50 HPF or $>5$ mitosis $/ 50 \mathrm{HPF}$ ), therefore, tumors are classified according to the prognostic risk as 'very low Risk' $(<2 \mathrm{~cm}$ and $<5$ mitosis/ 50HPF),'low Risk' ( $2-5 \mathrm{~cm}$ and $<5$ mitosis/50HPF), 'Medium Risk' ( $<5 \mathrm{~cm}$ and 6- 10 mitosis/50 HPFor 5-10 cm and $<5$ mitosis/ $50 \mathrm{HPF}$ ) and 'high Risk' $(>5$ $\mathrm{cm}$ and $>5$ mitosis $/ 50 \mathrm{HPF}, 10 \mathrm{~cm} /$ any mitosis index or any size and $>10$ mitosis/50HPF). Considering the prognostic risk in our series there were 5 tumors with low Risk (31.25\%). 3 tumors with moderate Risk (18.75\%) and 8 tumors with high Risk (50\%). Other poor prognostic factors are necrosis, infilteration, metastasis and hypercellularity $[43,44]$. In our series there were 3 cases $(18.75 \%)$ that had necrosis with poor prognosis.

Surgery is the primary treatment of choice in localized or potentially resectable GIST. It is important to avoid tumor rupture. The tumors are fragile and should be handled with care, aiming to achieve complete gross resection, with an intact pseudocapsule. Multiviseral and radical surgery should be avoided whenever possible: segmental or wedge resection with an aim to obtain histologically negative margin is sufficient. Resection should be accomplished with minimal morbidity. Lymphadenectomy is not required as GISTs have low incidence of nodal metastasis $[9,12,16]$. In our series, 15 patients $(93.75 \%)$ underwent surgery with complete surgical excision, 4 had partial gastrectomies, 2 had distal gastrectomies, one had local mesenteric excision with adjacent intestine, 5 had intestinal resection, one transverse colectomy,one anterior resection and one duoedonpancreatectomy for duodenal GIST.

All surgical interventions were open techniques. Laparoscopic approach was not used in our cases, as some authors don't recommend laparoscopic surgery for tumor $>2 \mathrm{~cm}$ or extra-wall neoplasm because of the increased risk of tumor breakage and peritoneal dissemination, 
[36] however, other authors consider this as a valid alternative in addition to open surgery [34].

Overall report 5-years survival rate after complete surgical resection of primary GIST is from $40 \%-55 \%[13,36]$.

Disease free survival is associated with tumor size and mitosis index. Therefore, low risk GIST has a 5-year disease free survival of $96 \%$, median-risk of $54 \%$ and high-Risk of $20 \%$ [45].

Disease free survival in our series was $87.5 \%$ at 4.5 years in all cases. Only 2 cases had liver metastasis, one case had small metastasis in segment VII of the right lobe of the liver in which segmentectomy (metastatectomy) was carried out. The second one was huge liver metastasis therefore put on Imatinib therapy since 2 years with little response.

Advanced and metastatic GIST (peritoneal dissemination or long distant metastasis (liver/lung) represent a treatment challenge. Until recently, overall survival of these patients was $<1$ year and 5 -years survival was only $20 \%$ [46].

Imatinib Mesylate, a tyrosine kinase inhibitor, plays a key role in the management of GISTs. It can be used as neoadjuvant therapy, adjuvant therapy and to treat tumor recurrence [47]. Its mechanism inhibits c-KIT tyrosine-kinase, which has a positive effect over c-KIT positive GIST. Several studies confirmed the beneficial effect of this medication in advanced GIST.

Consensus [35] and expert guidelines indicate Imatinib therapy may increase survival in patients with c-KIT-positive advanced GIST, allowing some patients to undergo primary surgery then to start as initial dose of Imatinib $400 \mathrm{mg}$ /day (except for exon q mutation on c-kit, changing dose to $800 \mathrm{mg} /$ day).

Early response will be assessed after 2-4 weeks of therapy using CT and PET scan (ideally) in order to determine functional response. In case of response, treatment will be continued until maximum response is achieved (3-6 months) and patient will undergo surgery if total resection is possible [48].

In this series, we have 5 patients who received Imatinib $400 \mathrm{mg} /$ day for 6 months as neoadjuvant therapy one of them had advanced gastric GIST, after 6 months of Imatinib therapy there was a dramatic response and the patient became candidate for surgical resection.

Postoperative Imatinib therapy has been reserved for patient with high risk of recurrence although there is insufficient evidence about optimal length of such therapy [49]. In our series all patients received Imatinib as adjuvant therapy for at least 6 months.

Metastatic GIST in the liver in the commonest site followed by peritoneal cavity, but can also occur in bone, skin, soft tissue and lymph node [50].

Patient with hepatic metastasis who is medically fit and with surgically accessible but focally progressive disease should be considered for resection. The rationale behind this approach is to eliminate of drug-resistance clones that will allow ongoing therapy with Imatinib [51].

Surgery in metastatic liver patients is a case based decision. Residual tumor resection is safe but multifocal resection is not recommended without considering the patient's performance status and personal situation [51,52].

When surgery may not be possible, limited evidence exists that similar benefits could be obtained from other nonsurgical ablative techniques such as radiofrequency ablation or embolization $[53,54]$.
In our series we have 2 patients with liver metastasis one of them cured with surgical resection and adjuvant Imatinab therapy, the other case had huge focal hepatic metastasis from colonic GIST and was not considered a candidate for surgery, had received the Imatinib therapy with poor response.

\section{Conclusion}

Gastrointestinal stromal tumor (GIST) is a complex and challenging disease requiring an effective multidisciplinary management team involving integrated specilities such as a pathologist, radiologist, gastroenterologist, oncologist, and a surgeon for better outcome of such cases.

\section{Conflict of interest}

The authors have no conflict of interest to report.

\section{References}

1. Nishida T, Hirota S (2000) Biological and clinical review of stromal tumors in the gastrointestinal tract. Histol Histopathol 15: 1293-1301.

2. Rubin BP, Heinrich MC, Corless CL (2007) Gastrointestinal stromal tumour. Lancet 369: 1731-1741.

3. Demetri GD, Benjamin RS, Blanke CD, Blay JY, Casali P, et al. (2007) NCCN Task Force report: management of patients with gastrointestinal stromal tumor (GIST)--update of the NCCN clinical practice guidelines. J Natl Compr Canc Netw 5 Suppl 2: S1-29.

4. Thomas RM, Sobin LH (1995) Gastrointestinal cancer. Cancer 75: 154-170.

5. Miettinen M, Lasota J, Sobin LH (2005) Gastrointestinal stromal tumors of the stomach in children and young adults: a clinicopathologic, immunohistochemical, and molecular genetic study of 44 cases with long-term follow-up and review of the literature. Am J Surg Pathol 29: 1373-1381.

6. Beham AW, Schaefer IM, Schüler P, Cameron S, Ghadimi BM (2012) Gastrointestinal stromal tumors. Int J Colorectal Dis 27: 689-700.

7. Miettinen M, Sarlomo-Rikala M, Lasota J (1999) Gastrointestinal stromal tumors: recent advances in understanding of their biology. Hum Pathol 30: 1213-1220.

8. Hatch KF, Blanchard DK, Hatch GF 3rd, Wertheimer-Hatch L, Davis GB, et al (2000) Tumors of the rectum and anal canal. World J Surg 24: 437-443.

9. Pidhorecky I, Cheney RT, Kraybill WG, Gibbs JF (2000) Gastrointestinal stromal tumors: current diagnosis, biologic behavior, and management. Ann Surg Oncol 7: 705-712.

10. Corless CL, Fletcher JA, Heinrich MC (2004) Biology of gastrointestinal stromal tumors. J Clin Oncol 22: 3813-3825.

11. Tornillo L, Terracciano LM (2006) An update on molecular genetics of gastrointestinal stromal tumours. J Clin Pathol 59: 557-563.

12. Fletcher CD, Berman JJ, Corless C, Gorstein F, Lasota J, et al. (2002) Diagnosis of gastrointestinal stromal tumors: A consensus approach. Hum Pathol 33: 459-465.

13. DeMatteo RP, Lewis JJ, Leung D, Mudan SS, Woodruff JM, et al. (2000) Two hundred gastrointestinal stromal tumors: recurrence patterns and prognostic factors for survival. Ann Surg 231: 51-58.

14. Machairas A, Karamitopoulou E, Tsapralis D, Karatzas T, Machairas N, et al. (2010) Gastrointestinal stromal tumors (GISTs): an updated experience. Dig Dis Sci 55: 3315-3327.

15. Dei Tos AP, Laurino L, Bearzi I, Messerini L, Farinati F; Gruppo Italiano Patologi Apparato Digerente (GIPAD); Società Italiana di Anatomia Patologica e Citopatologia Diagnostica/International Academy of Pathology, et al. (2011) Gastrointestinal stromal tumors: the histology report. Dig Liver Dis 43 Suppl 4: S304-309.

16. Stamatakos M, Douzinas E, Stefanaki C, Safioleas P, Polyzou E, et al. (2009) Gastrointestinal stromal tumor. World J Surg Oncol 7: 61.

17. Choi H, Charnsangavej C, Faria SC, Macapinlac HA, Burgess MA et al. (2007) Correlation of computed tomography and positron emission tomography in patients with metastatic gastrointestinal stromal tumor treated at a single institution with imatinib mesylate: proposal of new computed tomography response criteria. J Clin Oncol 25: 1753-1759. 
18. Young H, Baum R, Cremerius U, Herholz K, Hoekstra O, et al. (1999) Measurement of clinical and subclinical tumor response using [18F]fluorodeoxyglucose and positron emission tomography: review and 1999 EORTC recommendations. European Organization for Research and Treatment of Cancer (EORTC) PET Study Group. Eur J Cancer) 35: 1773-1782.

19. Berman J, O'Leary TJ (2001) Gastrointestinal stromal tumor workshop. Hum Pathol 32: 578-582.

20. Sepe PS, Brugge WR (2009) A guide for the diagnosis and management of gastrointestinal stromal cell tumors. Nat Rev Gastroenterol Hepatol 6: 363-371.

21. Wang D, Zhang Q, Blanke CD, Demetri GD, Heinrich MC, et al. (2012) Phase II trial of neoadjuvant/adjuvant imatinib mesylate for advanced primary and metastatic/recurrent operable gastrointestinal stromal tumors: long-term followup results of Radiation Therapy Oncology Group 0132. Ann Surg Oncol 19: 1074-1080.

22. Joensuu H (2006) Gastrointestinal stromal tumor (GIST). Ann Oncol 17 Supp 10: $\times 280-286$.

23. Walker P, Dvorak AM (1986) Gastrointestinal autonomic nerve (GAN) tumor. Ultrastructural evidence for a newly recognized entity. Arch Pathol Lab Med 110: 309-316.

24. Mazur MT, Clark HB (1983) Gastric stromal tumors. Reappraisal of histogenesis. Am J Surg Pathol 7: 507-519.

25. Hirota S, Isozaki K, Moriyama Y, Hashimoto K, Nishida T, et al. (1998) Gain-offunction mutations of c-kit in human gastrointestinal stromal tumors. Science 279: 577-580.

26. Kim KM, Kang DW, Moon WS, Park JB, Park CK, et al. (2005) Gastrointestinal stromal tumors in Koreans: it's incidence and the clinical, pathologic and immunohistochemical findings. J Korean Med Sci 20: 977-984

27. Goettsch WG, Bos SD, Breekveldt-Postma N, Casparie M, Herings RM, et al (2005) Incidence of gastrointestinal stromal tumours is underestimated: results of a nation-wide study. Eur J Cancer 41: 2868-2872.

28. Gold JS, Dematteo RP (2006) Combined surgical and molecular therapy: the gastrointestinal stromal tumor model. Ann Surg 244: 176-184.

29. Langer C, Gunawan B, Schüler P, Huber W, Füzesi L, et al. (2003) Prognostic factors influencing surgical management and outcome of gastrointestinal stromal tumours. Br J Surg 90: 332-339.

30. Miettinen M, El-Rifai W, H L Sobin L, Lasota J (2002) Evaluation of malignancy and prognosis of gastrointestinal stromal tumors: a review. Hum Pathol 33: 478-483

31. Nishida T, Takahashi T, Miyazaki Y (2009) Gastrointestinal stromal tumor: a bridge between bench and bedside. Gastric Cancer 12: 175-188.

32. Miettinen M, Lasota J (2003) Gastrointestinal stromal tumors (GISTs): definition, occurrence, pathology, differential diagnosis and molecular genetics. Pol J Pathol 54: 3-24.

33. Sánchez Hidalgo JM, Muñoz Casares FC, Rufian Peña S, Naranjo Torres A, Ciria Bru R, et al. (2007) [Gastrointestinal stromal tumors (GIST): factors predictive of survival after R0-cytoreduction]. Rev Esp Enferm Dig 99: 703-708.

34. Martín-Lorenzo JG, Aguayo-Albasini JL, Torralba-Martínez JA, Lirón-Ruiz R, Giménez-Bascuñana A, et al. (2006) [Gastrointestinal stromal tumors. Diagnosis, prognosis and current surgical treatment. Follow-up of 18 treated patients]. Cir Esp 79: 22-27.

35. Blay JY, Bonvalot S, Casali P, Choi H, Debiec-Richter M, et al. (2005) Consensus meeting for the management of gastrointestinal stromal tumors. Report of the GIST Consensus Conference of 20-21 March 2004, under the auspices of ESMO. Ann Oncol 16: 566-578.

36. Eizaguirre-Zarza B, Burgos-Bretones J (2006) GIST tumors. A literature review. Rev ESP Patol 39: 209-218.

37. Nowain A, Bhakta H, Pais S, Kanel G, Verma S (2005) Gastrointestinal stromal tumors: clinical profile, pathogenesis, treatment strategies and prognosis. J Gastroenterol Hepatol 20: 818-824.

38. Ha CY1, Shah R, Chen J, Azar RR, Edmundowicz SA, et al. (2009) Diagnosis and management of GI stromal tumors by EUS-FNA: a survey of opinions and practices of endosonographers. Gastrointest Endosc 69: 1039-1044.

39. Antoch G, Kanja J, Bauer S, Kuehl H, Renzing-Koehler K, et al. (2004) Comparison of PET, CT, and dual-modality PET/CT imaging for monitoring of imatinib (STI571) therapy in patients with gastrointestinal stromal tumors. J Nucl Med 45: 357-365.

40. Therasse P, Arbuck SG, Eisenhauer EA, Wanders J, Kaplan RS, et al. (2000) New guidelines to evaluate the response to treatment in solid tumors. European Organization for Research and Treatment of Cancer, National Cancer Institute of the United States, National Cancer Institute of Canada. J Natl Cancer Inst 92: 205-216.

41. Padhani AR, Ollivier L (2001) The RECIST (Response Evaluation Criteria in Solid Tumors) criteria: implications for diagnostic radiologists. Br J Radiol 74: 983-986.

42. Singer S, Rubin BP, Lux ML, Chen CJ, Demetri GD, et al. (2002) Prognostic value of KIT mutation type, mitotic activity, and histologic subtype in gastrointestinal stromal tumors. J Clin Oncol 20: 3898-3905.

43. Huang HY, Huang WW, Lin CN, Eng HL, LiSH, etal. (2006) Immunohistochemical expression of $\mathrm{p} 16 \mathrm{INK} 4 \mathrm{~A}, \mathrm{Ki}-67$, and $\mathrm{Mcm} 2$ proteins in gastrointestinal stromal tumors: prognostic implications and correlations with risk stratification of $\mathrm{NIH}$ consensus criteria. Ann Surg Oncol 13: 1633-1644.

44. Nemoto Y, Mikami T, Hana K, Kikuchi S, Kobayashi N, et al. (2006) Correlation of enhanced cell turnover with prognosis of gastrointestinal stromal tumors of the stomach: relevance of cellularity and p27kip1. Pathol Int 56: 724-731.

45. Rutkowski P, Nowecki ZI, Michej W, Debiec-Rychter M, WoÅ`niak A, et al (2007) Risk criteria and prognostic factors for predicting recurrences after resection of primary gastrointestinal stromal tumor. Ann Surg Oncol 14: 2018 2027.

46. Artigas-Raventós V, López-Pousa A (2006) Tumores de la estroma gastrointestinal: nuevos conceptos y estrategias terapéuticas multidisciplinares médico-quirúrgicas. Cir ESP 79: 1-2.

47. Cassier PA, Blay JY (2011) Gastrointestinal stromal tumors of the stomach and duodenum. Curr Opin Gastroenterol 27: 571-575.

48. Fernández JA, Parrilla $P(2009)$ [Surgical treatment of an advanced GIST the age of imatinib]. Cir Esp 86: 3-12.

49. Deshaies I, Cherenfant J, Gusani NJ, Jiang Y, Harvey HA, et al. (2010) Gastrointestinal stromal tumor (GIST) recurrence following surgery: review of the clinical utility of imatinib treatment. Ther Clin Risk Manag 6: 453-458.

50. Miettinen M, Lasota J (2006) Gastrointestinal stromal tumors: review on morphology, molecular pathology, prognosis, and differential diagnosis. Arch Pathol Lab Med 130: 1466-1478.

51. Kee D, Zalcberg JR (2012) Current and emerging strategies for the management of imatinib-refractory advanced gastrointestinal stromal tumors. Ther Adv Med Oncol 4: 255-270.

52. Demetri GD, von Mehren M, Antonescu CR, DeMatteo RP, Ganjoo KN, et al. (2010) NCCN Task Force report: update on the management of patients with gastrointestinal stromal tumors. J Natl Compr Canc Netw 8 Suppl 2: S1-41.

53. Kobayashi K, Szklaruk J, Trent JC, Ensor J, Ahrar K, et al. (2009) Hepatic arterial embolization and chemoembolization for imatinib-resistant gastrointestina stromal tumors. Am J Clin Oncol 32: 574-581.

54. Yamanaka T, Takaki H, Nakatsuka A, Uraki J, Fujimori M, et al. (2013) Radiofrequency ablation for liver metastasis from gastrointestinal stromal tumor. J Vasc Interv Radiol 24: 341-346. 